\title{
A Local Wisdom - Based Good Indonesia Book: Its Effectiveness in Teaching Indonesian as Foreign Language For The A-1 Level
}

\author{
Pujiati Suyata $^{1}$ and Hermanto ${ }^{2}$ \\ ${ }^{1}$ Ahmad Dahan University, Indonesia \\ ${ }^{2}$ Ahmad Dahlan University, Indonesia \\ 1pujiati.suyata@mp.uad.ac.id, 2hermanto@pbsi.uad.ac.id
}

\begin{abstract}
Currently there is an increasing interest in learning the Bahasa Indonesia for foreign learners or the "BIPA". Accordingly a well organized plans for its implementation would necessary. One of them would be a valid and unique textbook of the Bahasa Indonesia. This research aimed at developing a local wisdom-based textbook of Good Indonesia. The proposed textbook has to be validated empirically with good result. An Experimental method was used. The proposed textbook was empirically validated using Pre-test - Posttest Control Group Experimental Design. Data collection was test, questioner, and interview. A statistical was used with the SPPS program: t-test. The research results include (1) There was no different in the pretest achievement of the Bahasa Indonesia between the Level A-1 Darmasiswa with the book of Good Indonesia and the class using ordinary book $(t-580$, found no significant $p \geq$ 0.05. (2) After the experiment there was different in the post test achievement $t$ 3.157 found significant at $p \leq 0,05$. It meant the proposed book was effective and could be used to learn the bahasa Indonnesia for foreign language the A-1 level, (3) The conclusion was endorsed by the interview with the students and the lectures.
\end{abstract}

Keywords: Local Wisdom, Good Indonesia Book, Teaching Indonesian, Foreign Language.

\section{PENDAHULUAN}

Saat ini, bahasa Indonesia diajarkan di berbagai negara di dunia. Program Bahasa Indonesia untuk Penutur Asing (BIPA)) mencapai 251 lembaga, berada di 22 negara. Citra positif masyarakat Indonesia di dunia internasional terbangun berkat adanya pembelajaran bahasa dan budaya untuk orang asing tersebut [1]; [2]; [3].

Program Darmasiswa merupakan salah satu program BIPA yang selama ini dikembangkan pemerintah dalam rangka pengenalan dan pembelajaran bahasa dan budaya Indonesia di dunia internasional. Universitas Ahmad Dahlan merupakan salah satu universitas yang menyelenggarakan program Darmasiswa tersebut. Pembelajar BIPA dari tahun ke tahun semakin bertambah. Dalam rangka pembelajaran BIPA yang handal, diperlukan buku ajar yang mendukungnya. Badan Bahasa telah meluncurkan buku ajar "Sahabatku Indonesia" 
Namun demikian, dalam pelaksanaannya, buku tersebut perlu ditambah dengan buku-buku lain sebagai suplemen. [4] menegaskan, pengajar BIPA hendaknya jangan terpaku pada satu sumber materi ajar saja. Perlu penguatan sumber materi ajar lain sebagai materi tambahan, Adanya materi tambahan ini akan membuat pembelajaran BIPA lebih kaya. Sejauh ini, belum ada materi tambahan sebagai suplemen untuk pembelajaran BIPA tersebut. Begitu pentingnya buku suplemen pembelajaran BIPA yang handal, perlu dilakukan penelitian tentang hal itu. Tujuan penelitian ini adalah menguji keefektifan secara empirik buku "Indonesia Bagus" berbasis Kearifan Lokal dalam pembelajaan BIPA Level A-1.

\section{KAJIAN TEORI}

Materi ajar merupakan bagian terpenting dalam proses pembelajaran. Semua materi yang mendukung tujuan-tujuan pembelajaran yang disebut dengan istilah kompetensi dasar dapat disebut sebagai materi ajar. Terkait dengan pembelajaran BIPA, secara materi, semua hal terkait bahasa Indonesia menjadi bagian dalam pembelajaran BIPA. Materi membaca, misalnya, teknik membaca yang tepat perlu diberikan pada mahasiswa [5]; [7]. Namun demikian, pemilihan materi harus cermat dan hati-hati karena pembelajar BIPA memiliki tujuan yang berbeda dalam belajar BIPA. Oleh karena itu, materinya juga akan berbeda satu dengan yang lainnya.

Menurut [6] dalam mencapai hasil pengajaran berkualitas tinggi untuk setiap mata pelajaran, buku teks itu harus dilengkapi, dibantu, dan ditunjang oleh buku lainnya, seperti: 1) buku suplemen, 2) buku pegangan guru, 3) buku sumber atau acuan lain yang relevan. Buku suplemen merupakan buku kerja yang berfungsi menuntun siswa untuk berlatih, berpraktik dan mencobakan teori-teori yang sudah dipelajari pada buku pokok. Nama lain untuk buku suplemen adalah buku pelengkap, buku tambahan, dan buku kerja.

Buku suplemen merupakan buku pelajaran pelengkap yang berisi pengayaan informasi untuk melengkapi buku pelajaran pokok. Buku tersebut berfungsi memperkaya pengetahuan dan pengalaman pembelajar. Suplemen merupakan pendamping buku teks utama bukan buku pegangan pokok, materi buku berkaitan dengan standar kompetensi dan kompetensi dasar sesuai dengan silabus yang berlaku saat ini.

Rancangan buku suplemen BIPA perlu disusun dengan memperhatikan kondisi pembelajar. Pembelajar BIPA adalah pembelajar yang telah memiliki bahasa pertama dan memiliki latar belakang budaya yang berbeda. Tujuan pembelajar BIPA juga sangat beragam. Ada siswa yang bertujuan hanya untuk belajar percakapan praktis saja, untuk mampu membaca dan menulis. Ada pula yang bertujuan untuk studi di Indonesia. Usia pembelajar yang beragam juga harus menjadi perhatian dalam pembelajaran BIPA [2]; [8].

Buku Indonesia Bagus dirancang untuk digunakan bagi pembelajarar BIPA level A1. Buku tersebut terdiri atas 9 topik terkait dengan keperluan mahasiswa level awal, seperti perkenalan, transportasi, aktivitas sehari-hari, dan sebagainya. Isi buku disesuaikan dengan kebutuhan mahasiswa dan budaya Indonesia yang menarik minat mahasiswa, seperti adat sopan santun, dan budaya. Rancangan buku tersebut telah tervalidasi dengan hasil "layak". Validasi dilakukan oleh berbagai ahli, yaitu ahli materi, pengajaran, dan ahli BIPA. Selanjutnya, perlu diketahui validasi secara empirik buku tersebut.

\section{METODE PENELITIAN}

Sesuai dengan tujuan penelitian, metode penelitian ini adalah eksperimental dengan desain 
Pretest Postest Control Group Desain. Ada dua kelompok, yaitu kelompok eksperimen yang dikenai pembelajaran dengan buku Indonesia Bagus dan kelompok yang diajar dengan buku yang biasanya digunakan. Sebelum pembelajaran berlangsung, dilakukan pre-test untuk mengetahui kemampuan awal kedua kelompok pembelajar. Setelah pembelajaran, terhadap kedua kelompok dilakukan post-test untuk mengetahui hasil akhir belajar BIPA. Jika hasil pre-test kedua kelompok tidak berbeda, tetapi hasil post-test berbeda, maka buku "Indonesia bagus" dapat dinyatakan efektif. Rancangan eskperimen menggunakan desain Pretest Postest Control Group Desain sebagai berikut.

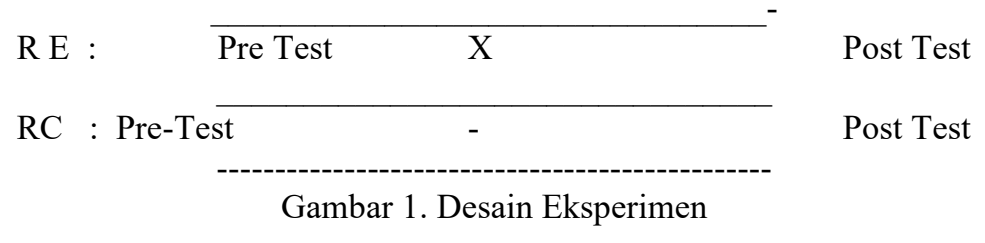

Subjek penelitian ini adalah 26 mahasiswa asing yang mengambil program Darmasiswa yang dikelola oleh Kantor Urusan Internasional (KUI) Universitas Ahmad Dahlan. Adapun objek penelitian ini adalah keefektifan buku suplemen "Indonesia Bagus".

Data diambil dengan tes, pengamatan, dan wawancara dengan instrumen tes, pedoman pengamatan, dan pedoman wawancara. Data dianalisis menggunakan rumus uji-t dengan bantuan program SPSS 25.0.

\section{HASIL DAN PEMBAHASAN}

Keefektifan buku "Indonesia Bagus" terlihat dari hal-hal sebagai berikut. Hasil pre-test kedua kelas tidak berbeda secara signifikan dengan t sebesar -.580 dan $p \geq 0.05$. Hal itu berarti kemampuan mereka sama pada awal pembelajaran. Selengkapnya dapat diamati Tabel 2 berikut.

Tabel 1. Independent Sample Pre-Test

\begin{tabular}{llllllll}
\hline & $F$ & Sig & $t$ & $d f$ & $\begin{array}{l}\text { Sig } \\
\text { tailed })\end{array}$ & $\begin{array}{l}95 \% \\
\text { Interval }\end{array}$ & Confodence \\
\hline $\begin{array}{l}\text { Equal } \\
\text { variance } \\
\text { assumed }\end{array}$ & 0,226 & 0,639 & -.580 & 24 & .567 & -2.22512 & -1.24825 \\
\hline $\begin{array}{l}\text { Equal } \\
\text { variance } \\
\text { not }\end{array}$ & - & - & -.590 & 23.926 & .561 & -2.19598 & -1.81816 \\
assumed & & & & & & & \\
\hline
\end{tabular}

Dari tabel tersebut tampak bahwa tidak terdapat perbedaan antara pre- test kelas yang diajar dengan buku "Sahabatku Indonesia" dan kelas yang diajar dengan buku "Sahabatku Indonesia" dan buku "Indonesia Bagus". Kemampuan awal kelas yang diajar dengan buku "Sahabatku Indonesa" dan diberikan suplemen buku "Indonesia Bagus" tidak berbeda antara kelas yang diajar dengan buku "Sahabatku Indonesia" saja. dengan $t=-.590$, yang tidak signifikan dengan $\mathrm{p} \geq 0,05$. 
Hal itu diperkuat dengan hasil analisis Post-test kelas eksperimen dan kelas kontrol sebagai berikut.

Tabel 2: Independent Sample Post-Test

\begin{tabular}{|c|c|c|c|c|c|c|c|}
\hline & $F$ & Sig & $T$ & $D f$ & $\begin{array}{l}\text { Sig } \\
\text { tailed) }\end{array}$ & $\begin{array}{l}95 \% \\
\text { Interval }\end{array}$ & Confodence \\
\hline $\begin{array}{l}\text { Equal } \\
\text { variance } \\
\text { assumed }\end{array}$ & 0,101 & 0,754 & -.4 .792 & 24 & 0,000 & -6.77869 & -6.77869 \\
\hline $\begin{array}{l}\text { Equal } \\
\text { variance } \\
\text { not } \\
\text { assumed }\end{array}$ & - & - & -4.736 & 21.950 & 0.000 & -6.81310 & -2.66309 \\
\hline
\end{tabular}

Dari tabel tersebut tampak bahwa terdapat perbedaan antara post test kelas yang diajar dengan buku "Indonesia Bagus" dan buku "Sahabatku Indonesia" dengan kelas yang diajar dengan buku "Sahabatku Indonesia" saja. Kelas yang diajar dengan buku "Sahabatku Indonesa" dan diberikan suplemen buku "Indonesia Bagus" lebih baik daripada kelas yang diajar dengan buku "Sahabatku Indonesia" saja. dengan t -4.792, yang signifikan dengan $\mathrm{p} \leq$ 0,05 .

Dengan demikian, dapat disimpulkan bahwa buku suplemen "Indonesia Bagus" efektif digunakan sebagai suplemen pembelajaran BIPA tingkat A-1. Dikatakan demikian sebab kondisi awal sama, tetapi berbeda pada akhir pembelajaran. Berbedanya kondisi tersebut karena digunakannya buku "Indonesia Bagus" sebagai suplemen buku ajar yang biasanya digunakan.

\section{DISKUSI}

Buku "Indonesia Bagus" berbasis kearifan lokal sebagai suplemen ternyata efektif dalam meningkatkan hasil belajar bahasa Indonesia bagi mahasiswa Darmasiswa di UAD. Hal itu searah dengan [9]; [10] bahwa kultur sangat berpengaruh pada mahasiswa asing yang belajar bahasa Indonesia, mahasiswa menjadi lebih antusias dan aktif dalam pembelajaran yang ditunjukkan oleh hasil belajar yang meningkat secara signifikan pada akhir pembelajaran. Sementara pemahaman terhadap kultur dapat ditingkatkan dengan mengaplikaskan pembelajaran yang integratif [11].

Keberadaan buku "Indonesia Bagus" juga didukung oleh hasil wawancara dengan dosen BIPA, Desi Kumalasari, SS, MA dan Galuh, SS, MA dosen BIPA. Buku paket BIPA, PPSK, terbitan Badan Bahasa terlalu sulit bagi mahasiswa Darmasiswa program A1. Diperlukan buku suplemen, seperti memasukkan. abjad pada awal buku. Dalam membaca, pada umumnya mahasiswa China dan Thailand sulit melafalkan /b/, /d/, dan /t/ [12]. Terkait buku Indonresia Bagus, aspek materi pas untuk pembelajar pemula (A1). Isi buku sesuai dengan indikator, komposisi warna sederhana dan tidak berlebihan, saling melengkapi antara materi budaya dan adat istiadat [13].

Selain itu, mahasiswa berpendapat bahwa kedua buku, "Sahabatku Indonesia" dan "Indonesia Bagus" dapat dipakai untuk pembelajaran BIPA, keduanya saling melengkapi, sangat berfungsi dalam belajar bahasa dan budaya Indonesia. 


\section{SIMPULAN}

Berdasarkan paparan di atas, dapat disimpulkan sebagai berikut. Pertama. Buku "Indonesia Bagus" efektif digunakan dalam pembelajaran BIPA level A-1. Buku tersebut dapat digunakan sebagai suplemen buku "Sahabatku Indonesia", buku paket yang diterbitkan PPSDK. Kedua. Buku suplemen "Indonesia Bagus" dapat didesiminasikan pada pembelajaran mahasiswa Darmasiswa Tingkat A1 pada pada tahun-tahun berikutnya. Selebihnya, buku tersebut juga dapat digunakan pada pembelajaran BIPA Tingkat A1 pada perguruan tinggi lain.

\section{REFERENCES}

[1] Sudaryanto. Pengajaran Bahasa Indonesia di Tiongkok: Sebuah Bunga Rampai. 2016.

[2] I. Suyitno. "Pengembangan Materi Pembelajaran BIPA berdasarkan Tujuan Belajar Pembelajar Asing”. Pidato Pengukuhan Guru Besar, Malang, 30 September., 2010.

[3] I. Widea. "Peranan Kebudayaan dalam Pembelajaran Bahasa Kedua: Teori dan Aplikasinya.”. Proceding Seminar Internasional Riska Bahasa. Literasi dan Budaya Bangsa, Editor Sumiyati, dkk., 2016.

[4] A. Kusmiatun. Mengenal BIPA dan Pembelajarannya. 2016.

[5] D. Zuchdi. Strategi meningkatkan kemampuan membaca. 2008.

[6] HG.Tarigan. Membaca sebagai suatu ketereampilan berbahasa. 2008.

[7] R. Flyoid, C. Elisabeth.. "An explanation of reading comprehension across development using model of reading". Psychology in the school (1-19) Retried from http/dacemirror.sci. hub.cc/10.1002/pits.21633., 2012.

[8] L. Muliastuti.. Bahasa Indonesia bagi Penutur Asing: Acuan Teori dan Pendekatan Pengajaran. 2017.

[9] S. Kundharu.. "Cultural and social change of foreign students in Indonesia: The influence of Javanese culture in teaching Indonesian as Foreign language (TISOL"). IOP conference series-earth and environmental science. Volume 126. Conference 1: 2015.

[10] K. Saddhono. "Teaching Indonesian as Foreign Language: Development of Instructional Material Based Javanese culture with scientific thematic approach". Proceeding of the internasional conference on teaching training and education ICTTE Vol 2, no. 1., 2016.

[11] Andayani. "Improving the language skills and local cultureal understanding with integrative Learning TISOL”. International Journal of Language and Linguistics, Vol. 3, 202, June., 2016.

[12] M.M. Bachore. "The Role of Mother Tongue Based Education in Insersing The Quality of Classroom Instruction: Opportunities and Challenges". Journal of Education and Literature Vol1, no 1 p 31-38.

[13] K. Saddhono, "Integrating culture in Indonesian language learning for foreign speakers at Indonesian universities,” J. Lang. Lit., vol. 6, no. 2, 2015. 